\title{
A!
}

This is an electronic reprint of the original article.

This reprint may differ from the original in pagination and typographic detail.

Ahmad, Zeeshan; Aryal, Janak; Ranta, Olli; Kaario, Ossi; Vuorinen, Ville; Larmi, Martti

\section{An Optical Characterization of Dual-Fuel Combustion in a Heavy-Duty Diesel Engine}

Published in:

SAE Technical Papers

DOI:

10.4271/2018-01-0252

Published: 01/01/2018

Document Version

Peer reviewed version

Please cite the original version:

Ahmad, Z., Aryal, J., Ranta, O., Kaario, O., Vuorinen, V., \& Larmi, M. (2018). An Optical Characterization of Dual-Fuel Combustion in a Heavy-Duty Diesel Engine. SAE Technical Papers, 2018-April.

https://doi.org/10.4271/2018-01-0252

This material is protected by copyright and other intellectual property rights, and duplication or sale of all or part of any of the repository collections is not permitted, except that material may be duplicated by you for your research use or educational purposes in electronic or print form. You must obtain permission for any other use. Electronic or print copies may not be offered, whether for sale or otherwise to anyone who is not an authorised user. 


\title{
An Optical Characterization of Dual-Fuel Combustion in a Heavy-Duty Diesel Engine
}

\author{
Zeeshan Ahmad, Janak Aryal, Olli Ranta, Ossi Kaario, Ville Vuorinen, Martti Larmi \\ Department of Mechanical Engineering, Aalto University School of Engineering, 02150-Espoo, Finland
}

\begin{abstract}
Dual fuel (DF) combustion technology as a feasible approach controlling engine-out emissions facilitates the concept of fuel flexibility in diesel engines. The abundance of natural gas $(90-95 \%$ methane) and its relatively low-price and the clean-burning characteristic has attracted the interest of engine manufacturers. Moreover, with the low $\mathrm{C} / \mathrm{H}$ ratio and very low sooting tendency of methane combined with high engine efficiency, makes it a viable primary fuel for diesel engines. However, the fundamental knowledge on in-cylinder combustion phenomena still remains limited and needs to be studied for further advances in the research on DF technology. The objective of this study is to investigate the ignition delay with the effect of, 1) methane equivalence ratio, 2) intake air temperature and 3) pilot ratio on the diesel-methane DFcombustion. Combustion phenomenon was visualized in a single cylinder heavy-duty diesel engine modified for DF operations with an optical access. The high-speed natural luminosity (NL) imaging technique was employed to record the temporally resolved incylinder combustion event at an operating load of approx. 10 bar IMEP at $1400 \mathrm{rpm}$. The results show that flame propagation becomes stable and sustained with an increase in either of the methane equivalence ratio, intake air temperature, or diesel amount. However, the sensitivity of each effect on the flame propagation and ignition delay was observed to be different. The effect of these parameters on DF combustion has been characterized with the help of NL images and corresponding cylinder pressure and net heat-release rate (HRR) data. The study also presents a detailed discussion on the analyzed ignition delay trends.
\end{abstract}

\section{Introduction}

Several studies of DF combustion have indicated the potential with the usage of two fuels to control the ignition delay process $[1][2][3][4][5]$. DF combustion is considered a practical solution in a short time to comply with stringent legislation of exhaust emissions. It is expected that the utilization of methane in the transportation sector will increase. The diesel-methane DF combustion realized in diesel engines with high compression ratio combines the traits of spark ignited and compression ignited combustion processes. In DF combustion, the low reactivity fuel (methane) is compressed and ignited by the auto-ignition of a small amount of high-reactivity fuel (diesel-pilot) close to the top-dead-center (TDC). The DF engines operated with methane at lean conditions produce lower NOx and $\mathrm{CO}_{2}$ emissions as compared to conventional diesel engines [6][7]. However, at low load conditions, the lean mixture of methane burns

Page 1 of 9 inefficiently due to unsuccessful flame propagation, which may lead to a significant emission of unburnt hydrocarbons (UHC) and carbon monoxide (CO) [6]. In contrast, high load conditions may cause NOx emission in high temperatures and due to an increase in the diesel fuel mass. Moreover, a significant reduction of soot emission from DF engines has also been reported [8][9][10].

The main challenges associated with DF combustion are knock and misfire that limit its operating window. Knock [11][12] occurs at high-load operating conditions while misfire [12] occurs at very lean conditions. The ignition delay time for the diesel-methane dual fuel combustion is considerably longer than for conventional diesel combustion and it varies over a wide range of methane equivalence ratios, intake air temperatures and the amount of diesel in the mixture. Furthermore, the ignition delay has a significant effect on the overall combustion phenomenon besides the engine performance and power output [13]. Karim et al. [1][14][15][3] conducted comprehensive research on DF combustion and reported that ignition delay depends on the type of the gaseous fuel and its concentration in the in-cylinder charge. They found that the length of the ignition delay was highly sensitive to the effective mean temperature of the in-cylinder charge. In addition, at lower temperature with smaller pilot amount; the combustion becomes unstable and leads to longer ignition delay. Masouleh et al. [4] have reported that the addition of methane has a retarding effect on diesel-pilot ignition and reduces the probability of collision between diesel and air molecules per unit time that leads to an increase in ignition delay. Moreover, they found that methane increases the ignition delay not only due to its concentration but also due to altered intermediate radical group formation. Several studies [13][1][3][16][17] investigate the effects of equivalence ratio, intake temperature and pilot amount on the ignition delay of DF combustion. The studies show that the increased pilot amount reduces the ignition delay insignificantly and increases the entrained volume of premixed methane during the pilot combustion. Moreover, the studies show that the extent of variations in the ignition delay is due to the changes in the mean mixture temperature. Few studies have attempted to understand DF combustion by in-cylinder visualization of combustion process. Schlatter et al. [2][5] conducted optical experiments in a rapid compression expansion machine (RCEM) based on $\mathrm{OH}^{*}$ chemiluminescence and Schlieren photography with simultaneous detection of $\mathrm{CH}^{*}$ and $\mathrm{C}_{2} *$ for $\mathrm{n}$-heptane and diesel-pilot DF combustion. Their work indicates that flame propagation becomes prominent and ignition delay increases with an increase in the methane quantity in the mixture. Moreover, ignition delays are longer at colder conditions. Dronniou et al. [18] investigated DF combustion optically at a wide range of equivalence ratios of premixed CNG. They recorded time resolved high-speed NL images 
and single cycle $\mathrm{OH}^{*}$ chemiluminescence. Through the experiments it was reported that flame propagation starts from multiple locations near the wall and progresses toward the center of the combustion chamber which is also observed by Nithyanandan et al. [8] and Khosravi et al. [19]. At higher equivalence ratio, flame propagation is prominent while at lower equivalence ratios, they reported inadequate methane consumption at the center of combustion chamber due to unsustainable flame propagation [18]. Carlucci et al. [6] have investigated the DF combustion based on combustion intensity and reported that when increasing the pilot amount, a combustion event with high luminosity can be observed.

Basic knowledge of DF combustion is still limited and in order to overcome the limitations, an experimental sequence was designed to understand the ignition process. High-speed NL imaging is a simple optical diagnostic approach to combustion characterization that relies on the information collected from the electromagnetic radiation spectrum of the combustion species and their scattered light. In DF combustion, gas chemiluminescence has a major contribution to the NL [19]; nevertheless, soot radiation contributes to NL as well at high load and low substitution rate of methane. This study investigates the diesel-methane DF combustion in a single-cylinder optical engine at two different methane equivalence ratios cases, intake air temperatures and pilot ratios and their effects on the ignition delay and overall combustion phenomenon.

\section{Experimental Setup}

\section{Engine and Imaging System}

Experiments were conducted in a heavy-duty diesel engine, AGCO84AWI 6-cylinder base engine modified for single cylinder dual fuel (DF) operations with an optical access. The engine specifications are listed in Table 1. The Bowditch extension [20] configuration was adopted in only one cylinder for optical access. An elongated bowlshaped piston reciprocates in the cylinder along a $45^{\circ}$ inclined mirror. The piston is housed with a borosilicate glass window in its crown. In the remaining five cylinders, steel weights were fitted into balancing dummy pistons to balance the mass of the elongated piston. Figure 1 illustrates the optical setup. In addition, Figure 2 shows a picture of the laboratory optical-engine. Prior to the engine test-run, the desired operating conditions and parameters were obtained by adjusting several auxiliary systems. The engine was preheated to $343 \mathrm{~K}$ to resemble the real production engine working conditions.

\section{Table 1. Heavy-duty engine specification}

\begin{tabular}{|l|l|}
\hline Engine Type & $\begin{array}{l}\text { 4-Stroke, Optical accessed Single } \\
\text { Cylinder engine for DF operations }\end{array}$ \\
\hline Displacement Volume & $1402 \mathrm{cc}$ \\
\hline Bore x Connecting Rod & $111 \times 145 \mathrm{~mm}$ \\
\hline Compression Ratio & $14.5: 1$ \\
\hline In-Cylinder Swirl Ratio & 2.7 \\
\hline Diesel-pilot Injection System & Bosch CRN13-20 Common rail \\
\hline Injector no. of holes x Diameter & $2 \times 0.138 \mathrm{~mm}$ \\
\hline Diesel-pilot injection pressure & 870 bar \\
\hline Methane Injection System & EG2000 gas Injectors \\
\hline RPM & 1400 \\
\hline
\end{tabular}

Page 2 of 9

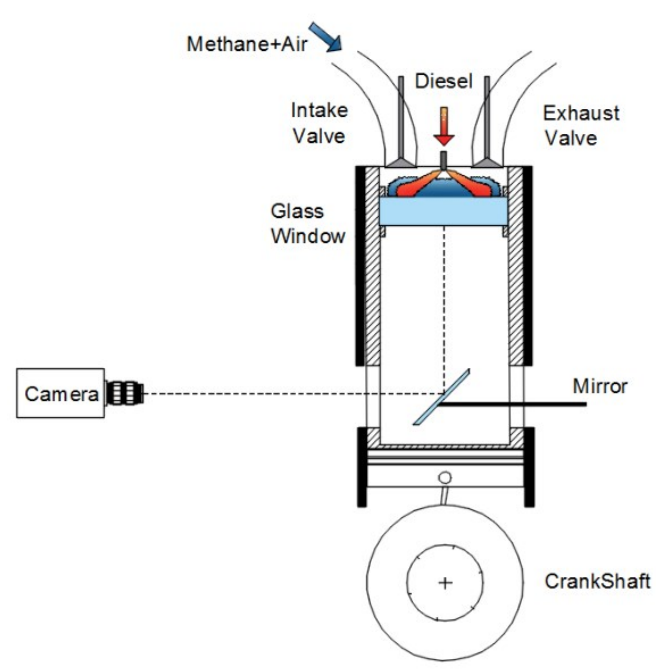

Figure 1. Illustration of optical engine setup and NL imaging system

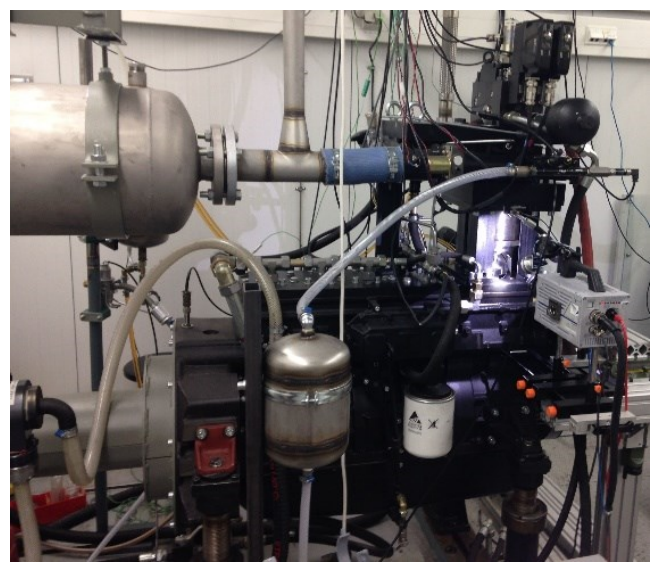

Figure 2. Optical engine setup with high-speed camera installed in place

The NL images from the bowl-shaped optical combustion chamber were recorded by Photron Fastcam APX-RS CMOS high-speed colour camera. The camera exposure was set to $33.33 \mu$ s at $9000 \mathrm{fps}$ and maximum resolution of $512 \times 512$ was applied. The specifications of the optical camera system are tabulated in Table 2 . The images were processed by using Matlab algorithms for image cropping, image intensity adjustments, edge-detection and temporal synchronization with the CAD. For boundary edge detection, the regions of maximum intensity gradient were detected as an edge from the blue channel of the NL images.

Table 2. Optical system specification

\begin{tabular}{|l|l|}
\hline Camera & $\begin{array}{l}\text { Photron Fastcam APX-RS 250k, } \\
\text { Color Camera }\end{array}$ \\
\hline Type & High-Speed CMOS, Bayer Filter \\
\hline Lens & Nikon AF Nikkor 28-70mm f/3.5 \\
\hline Frame rate & $9000 \mathrm{fps}$ \\
\hline Aperture & $\mathrm{f} / 3.5$ \\
\hline Exposure & $33.33 \mu \mathrm{s}$ \\
\hline Resolution & $512 \times 512$ \\
\hline
\end{tabular}




\section{Operating Method}

DF combustion was investigated at loads of $\sim 9-10$ bar IMEP, intake air pressure of $1.1 \mathrm{bar}$, the pilot injection pressure of $870 \mathrm{bar}$ and engine speed of $1400 \mathrm{rpm}$. Due to limitations stemming from the mechanical properties of piston glass window, a skip-fire protocol was implemented during engine runs. Every combustion cycle was followed by six skip-fired cycles. Each test point was run for 150 cycles, out of which 22 cycles were combustion cycles. The pilot fuel used in the test runs was commercial diesel fuel (EN590) [21] and the main fuel was $99.9 \%$ methane. Methane was injected into intake air manifold at 3.6 bar by two methane injectors at -365 CAD ATDC that was then inducted into the cylinder through the intake valves along with the intake air. The methane air mixture was later ignited by diesel-pilot, injected by a two-hole diesel injector at SOI $=-15 \mathrm{CAD}$ ATDC (electronic). The injection timing was chosen in a way that peak DF cylinder-pressures could be obtained closer to the firing TDC and work done by the combustion gases was most efficient. In a series of separate tests performed in the same optical engine, the spray was detected to emerge through the nozzle at SOI $=-11 \mathrm{CAD}$ ATDC (actual), four CADs later than the electronic injection signal. This fact has been accounted in calculating ignition delay in the forthcoming results section.

Cylinder pressure was measured with a Kistler pressure sensor that sampled the pressure data every 0.2 CADs, independent of the engine speed. The sampled pressure data were post-processed to measure the engine performance and to calculate the net heat-release rate (HRR) [22]. The ignition delay in combustion analysis was computed from the mean of HRR over 10 individual combustion cycles. The ignition delay was defined as the time interval between the SOI (actual spray emerging) and the instant where $5 \%$ of the cumulative heat release was achieved. The top-dead centre temperature was calculated by assuming isentropic compression. To quantify the injected air and fuel, Rheonik-015 Coriolis mass-flow-meters were employed. However, due to small amounts of diesel-pilot utilized during experiments, diesel mass was quantified by a series of tests conducted at same injection and ambient conditions as implemented in the present study. The pilot-quantification tests were conducted in a single cylinder full-metal engine, a counterpart of this optical engine. For each injection duration test, the engine was run for 20 minutes and diesel fuel tank weight was measured at every 2-minutes intervals that provided an average mass flow of injected diesel fuel at a certain injection duration.

A schematic field view of combustion chamber is presented in Figure 3 that provides the position of injector nozzle, fuel sprays, and inlet and exhaust valves in the cylinder. The diesel injector is located in the centre of the combustion chamber and fuel sprays axes represent actual diesel-pilot sprays position in the combustion chamber.

Moreover, a clockwise (CW) swirl rotation in the cylinder affects the mixing of fuels and combustion. The swirl ratios were measured at different valve lifts for the optical engine cylinder head by particle image velocimetry and paddle wheel. The measurements were compared with CFD predictions. More details can be found in [23].
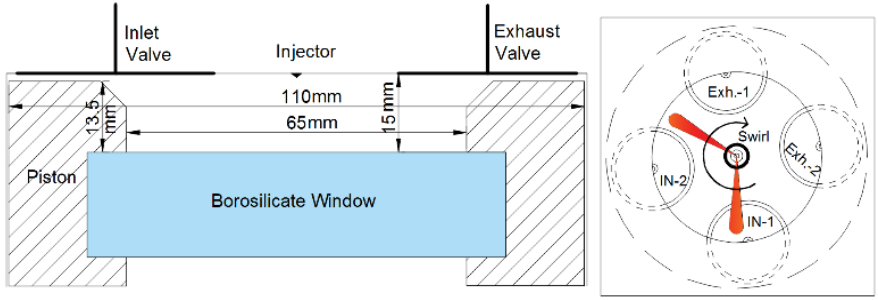

Figure 3. Schematic field view of the combustion chamber (CC) at 0-CAD (TDC). (Left): provides the dimensions and the visible field view of the CC (Right): provides the location of actual diesel-pilot sprays, inlet and exhaust valves and diesel-pilot injector as seen (solid-lines) through the camera.

The effects of methane equivalence ratio, diesel-pilot amount and intake air temperature on DF combustion are studied. It is worth noting that three-dimensional combustion phenomena are presented as two-dimensional NL images. Table 3 outlines test parameters for the study of the effect of methane equivalence ratio and intake air temperature on DF combustion. Two different methane equivalence ratios $(\phi \mathrm{CH} 4)$ were obtained by increasing the methane injection duration. Moreover, each $\phi_{\mathrm{CH} 4}$ was studied at three different intake air temperatures of $299 \mathrm{~K}, 315 \mathrm{~K}$ and $325 \mathrm{~K}$ that resulted in calculated isentropic top-dead-center temperatures (TTDC) of 744K, $780 \mathrm{~K}$ and $804 \mathrm{~K}$ respectively. In all test runs, the amount of diesel-pilot and all other parameters were kept constant.

Test parameters for the study of the effect of diesel-pilot ratio (PR) on DF combustion are listed in Table 4. The study analyzes two different PRs, which were obtained by increasing the pilot injection duration, and in turn, the diesel-pilot amount in the mixture. In these test runs, all other parameters were kept constant. However, the inducted air mass varied due to variations in engine operation. The PR test runs were examined with a constant methane equivalence ratio $\left(\phi_{\mathrm{CH} 4}=0.55\right)$ and at one intake air temperature of $299 \mathrm{~K}$ that resulted in isentropic $\mathrm{T}_{\mathrm{TDC}}=744 \mathrm{~K}$. Constant methane equivalence ratio (instead of constant charge energy) was chosen due to the observed ignition delay sensitivity to methane equivalence ratio.

Table 4. Operating test parameters for the study of the Pilot ratio (PR).

\begin{tabular}{|l|l|l|}
\hline$\phi_{\text {СH4 }}$ & 0.55 & 0.55 \\
\hline$\phi_{\text {TOTAL }}$ & 0.66 & 0.76 \\
\hline Pilot Ratio (PR) [\%] & 16.5 & 27.5 \\
\hline Diesel [mg/cycle] & 9.52 & 18.1 \\
\hline Methane [mg/cycle] & 41.88 & 41.65 \\
\hline $\begin{array}{l}\text { Total Injected Energy } \\
{[\mathrm{kJ} / \text { cycle] }}\end{array}$ & 2.51 & 2.87 \\
\hline IMEP [bar] & 8.72 & 9.44 \\
\hline
\end{tabular}

Table 3. Operating test parameters for the study of the effect of $\phi_{\mathrm{CH} 4}$ and $\mathrm{T}_{\mathrm{TDC}}$ on DF combustion. IMEP is the indicated mean effective pressure.

\begin{tabular}{|c|c|c|c|c|c|c|c|c|c|c|c|c|}
\hline \multirow[t]{2}{*}{$\phi_{\mathrm{CH} 4}$} & \multirow[t]{2}{*}{$\phi_{\mathrm{TOTAL}}$} & \multirow[t]{2}{*}{$\begin{array}{l}\text { Diesel } \\
{[\mathrm{mg} / \text { cycle }]}\end{array}$} & \multirow[t]{2}{*}{$\begin{array}{l}\text { Diesel-Pilot } \\
\text { Ratio (PR) [\%] }\end{array}$} & \multicolumn{3}{|c|}{ Methane $[\mathrm{mg} /$ cycle $]$} & \multicolumn{3}{|c|}{$\begin{array}{l}\text { Total Injected Energy } \\
{[\mathrm{kJ} / \text { cycle }]}\end{array}$} & \multicolumn{3}{|c|}{ IMEP [bar] } \\
\hline & & & & @744K & @ $780 \mathrm{~K}$ & (a) $804 \mathrm{~K}$ & (a)744K & @ $780 \mathrm{~K}$ & (a)804K & @744K & @ $780 \mathrm{~K}$ & (a)804K \\
\hline 0.57 & 0.71 & 9.52 & 16.5 & 40.46 & 40.46 & 40.94 & 2.44 & 2.44 & 2.46 & 8.86 & 8.7 & 8.7 \\
\hline 0.86 & 0.98 & 9.52 & 12.5 & 58.55 & 58.31 & 60.69 & 3.35 & 3.33 & 3.44 & 10.1 & 10.0 & 10.3 \\
\hline
\end{tabular}

Page 3 of 9

$01 / 24 / 2018$ 


\section{Results and Discussions}

\section{Effect of $\phi_{C H 4}$ and Intake Air Temperature $\left(T_{T D C}\right)$}

The ensemble NL images of two $\phi_{\mathrm{CH} 4}$ cases are presented in Figure 4 and 6, which exhibit the progression of DF combustion. Each figure represents a single $\phi_{\mathrm{CH} 4}$ case and provides a comparison between the NL images of DF combustion at different temperatures (TTDC) (as presented in Table 3). The NL images are presented at an interval of three CADs from the visible sign of the start of combustion CAD, detected under the tabulated optical system specifications. The crank angle degrees reported on each NL image are relative to the firing TDC. The NL images show the commencement of two distinct flame front reaction zones separated from each other at the early stage of the combustion as shown by edge detection in Figure 5 and 7. The edge detection affirms that the combustion starts from the two diesel sprays as two distinct reaction zones. The ignition spot of these reaction zones should be around the diesel-pilot spray region as depicted in Figure 3. However, it does not seem to be the case due to the $\mathrm{CW}$ in-cylinder swirl rotation and delay in the ignition. After the early phase of combustion, the premixed turbulent flame front grows with increasing intensity and propagate towards the center of the combustion chamber.

Having reached the intensity peak, the flame fronts commence to disappear. High-speed videos revealed that the intensity peak is achieved after the peak heat release and on average the flame front propagation vanishes at $\sim 37$ CAD ATDC in current test runs. It was observed that the flame fronts at the leanest $\phi_{\mathrm{CH} 4}=0.57$ case do not seem to cover the entire combustion chamber and the center of the combustion chamber is devoid of any luminosity coming from methane combustion, which might be due to the weaker flame propagation [1][14][5][18], as shown in Figure 4. Observing the NL images in Figure 4 and 6, the saturated high-intensity spots around the vicinity of the injector can be seen. These bright spots are due to the injector dribbling that creates locally fuel-rich zones leading to soot formation, a phenomenon also reported by Nithyanandan [8], Dronniou [18] and Khosravi [19]. At conditions closer to stoichiometry $\left(\phi_{\mathrm{CH} 4}=0.86\right.$, see Figure 6$)$, apart from the dribbling, the evaporated diesel fuel forms a richer mixture that burns with the orange/yellowish flames close to the periphery of the combustion chamber and causes soot formation. The TDC temperature and equivalence ratio have noticeable effects on DF combustion. At conditions closer to stoichiometric, the flame fronts are distinguishable and stronger and cover the entire combustion chamber, also reported by Schlatter et al. [2][5].

In Figure 8 and 9, the heat-release-rate (HRR) curves show a twostage combustion. In HRR curves, the first peak refers to the first stage of combustion triggered by the combustion of diesel-pilot and entrained methane-air mixture, along with the subsequent flame front propagation as explained by Karim's conceptual combustion model [1][14]. It was observed that at a higher TDC temperature, the burnt fraction of the methane-air mixture increases during the first stage marginally. The second stage of combustion is the result of the autoignition of the remaining unburnt methane-air mixture or flame front propagation or a combined effect of both combustion modes [24][25]. The auto-ignition of the methane-air mixture at the second stage is caused by the increasingly higher in-cylinder temperature. It was observed that the second stage becomes more distinctive both at higher TDC temperatures and at higher methane equivalence ratios. In HRR curve of $\phi_{\mathrm{CH} 4}=0.57$ (Figure 8 ) at $\mathrm{T}_{\mathrm{TDC}}=804 \mathrm{~K}$, the third peak is believed to be the continuation of the second stage combustion.

Page 4 of 9
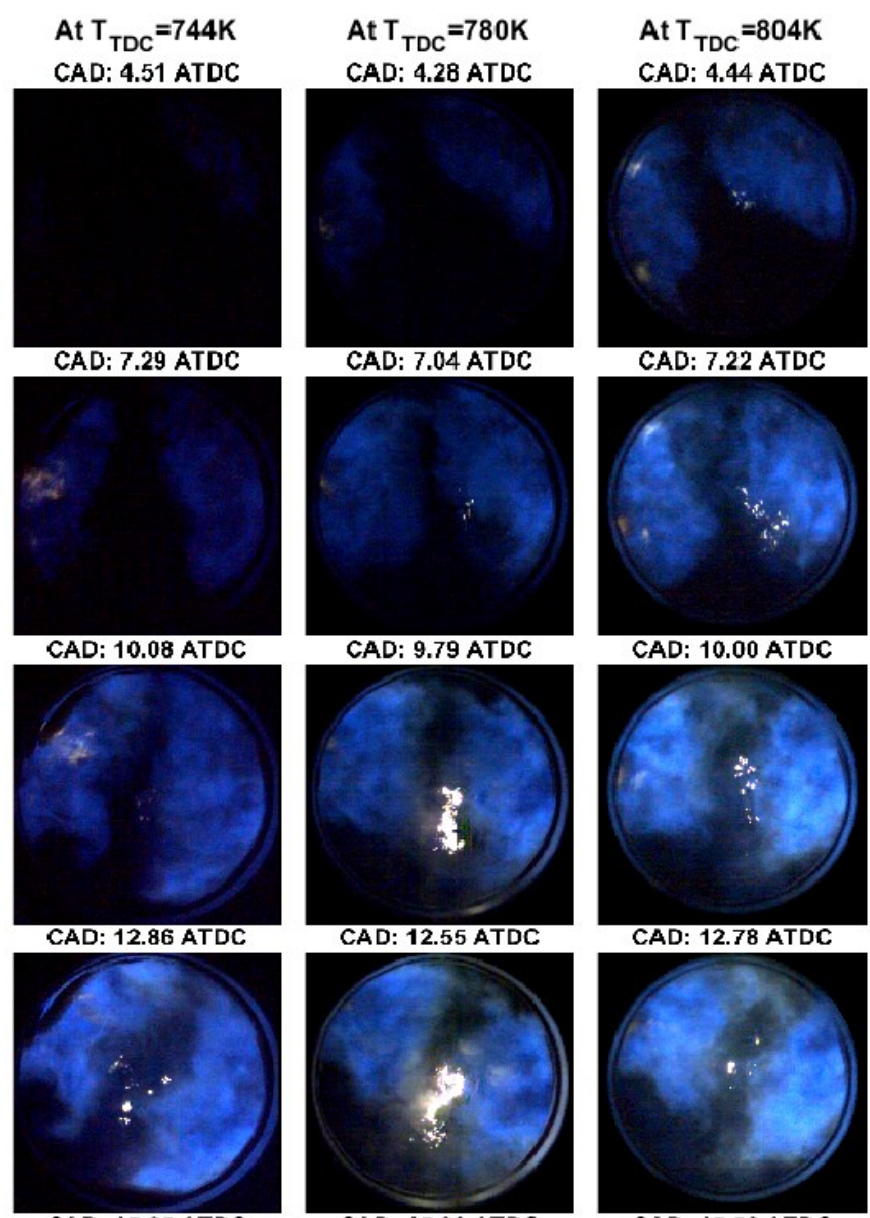

CAD: 7.22 ATDC

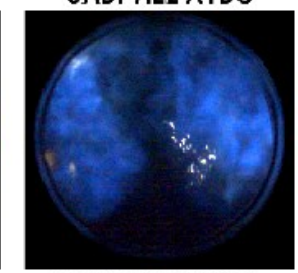

CAD: 10.00 ATDC
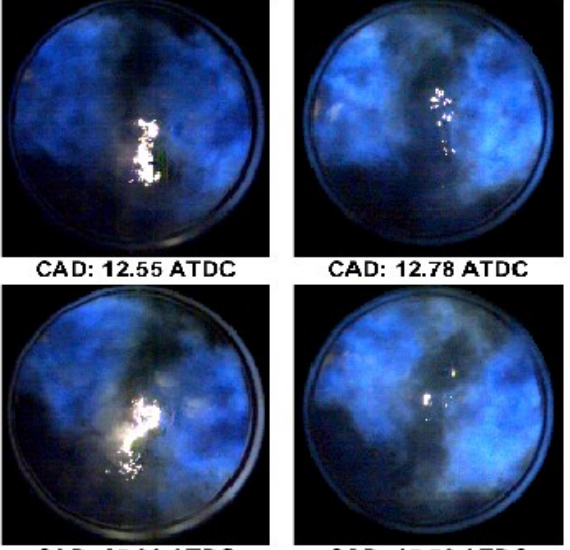

CAD: 12.78 ATDC
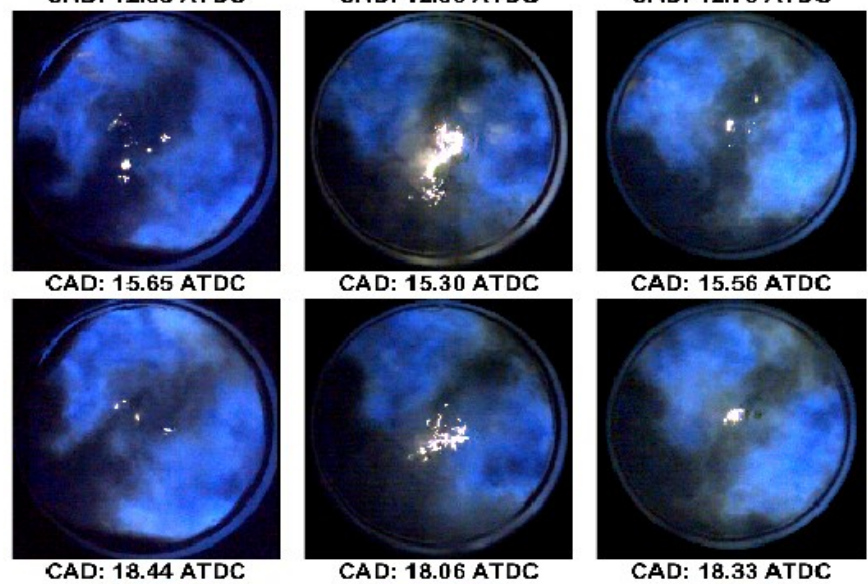

CAD: 15.56 ATDC
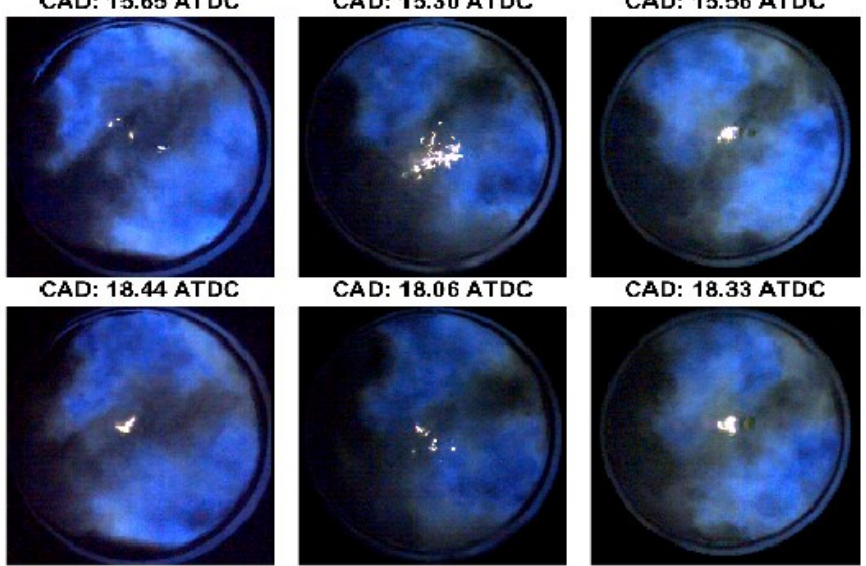

CAD: 18.06 ATDC

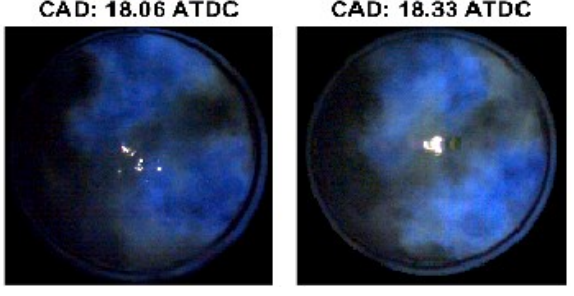

Figure 4. Representative NL images of DF combustion at $\phi_{\mathrm{CH} 4}=0.57$ and at different $T_{T D C}$
CAD: 7.29 ATDC
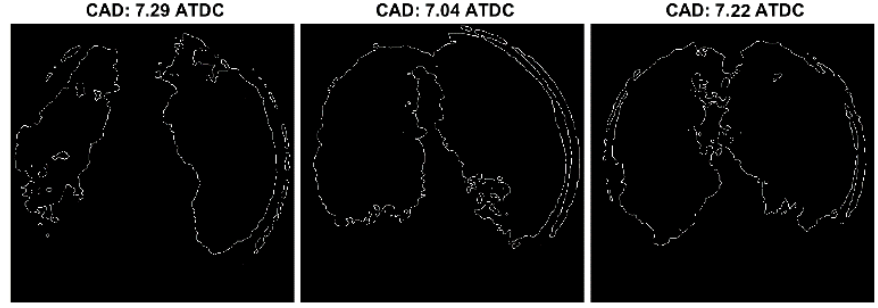

Figure 5. Boundary edges of two distinct reaction zones from the blue channel of NL images at $\sim 7 \mathrm{CAD} \mathrm{ATDC}$ at $\phi_{\mathrm{CH} 4}=0.57$ (relative to Figure 4) 

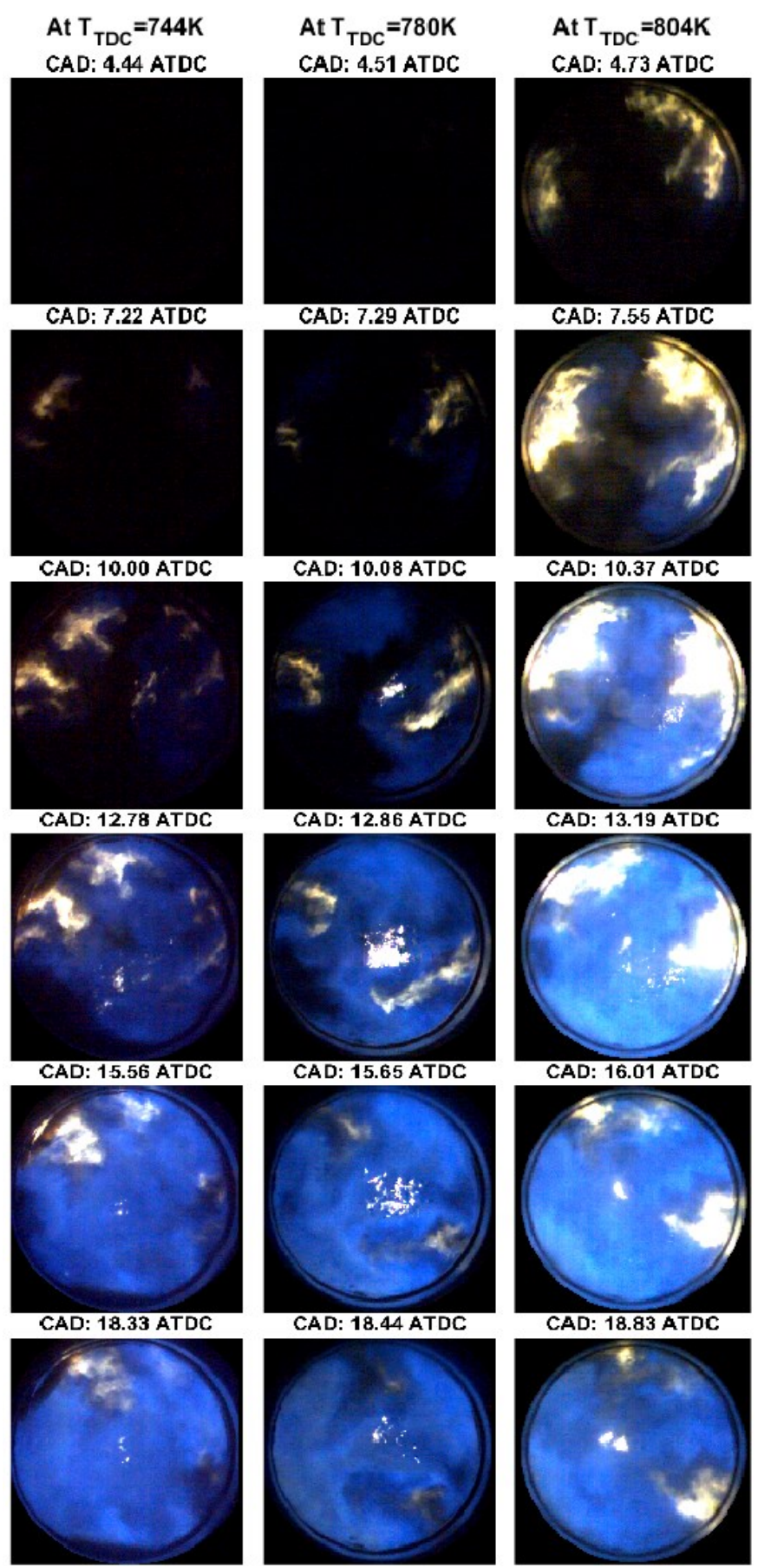

Figure 6. Representative NL images of DF combustion at $\phi_{\mathrm{CH} 4}=0.86$ and at different $\mathrm{T}_{\mathrm{TDC}}$
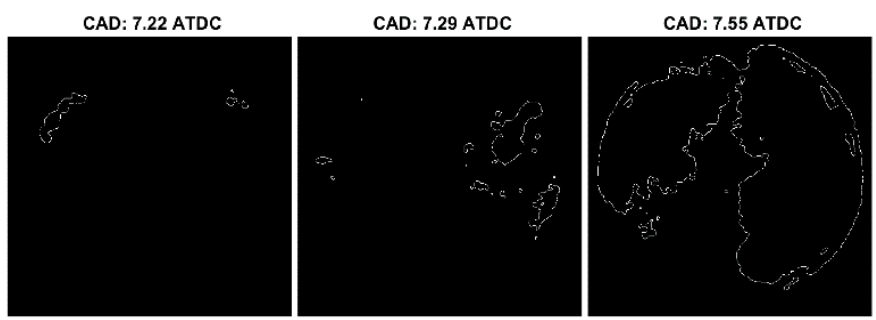

Figure 7. Boundary edges of two distinct reaction zones from the blue channel of NL images at $\sim 7$ CAD ATDC at $\phi_{\mathrm{CH} 4}=0.86$ (relative to Figure 6)

Page 5 of 9
Moreover, the CAD-resolved high-speed videos along with HRR curves reveal that the burning of the droplets at the center of the combustion chamber (injector dribbling) is an indicator of a rapid temperature increase around the central area of the combustion chamber [18]. Furthermore, it was observed that the HRR shapes are sensitive to the TDC temperature, equivalence ratio, and operating load conditions. These HRR shapes are found to be different from the shapes obtained at high loads and higher diesel-pilot amounts for the similar base engine in Pettinen [21], where a short combustion phase of diesel-pilot and entrained premixed methane-air combustion is followed by the bulk methane-air mixture combustion. In contrast to Pettinen, the current DF combustion test yielded a considerably longer time available for diesel-pilot to mix with in-cylinder charge due to lower engine load, and hence lower gas pressure and density. Thus, premixed combustion of diesel-pilot overlaps with the premixed methane-air combustion, which appears as the first stage of combustion. Diesel-pilot seems to be consumed entirely at this stage.

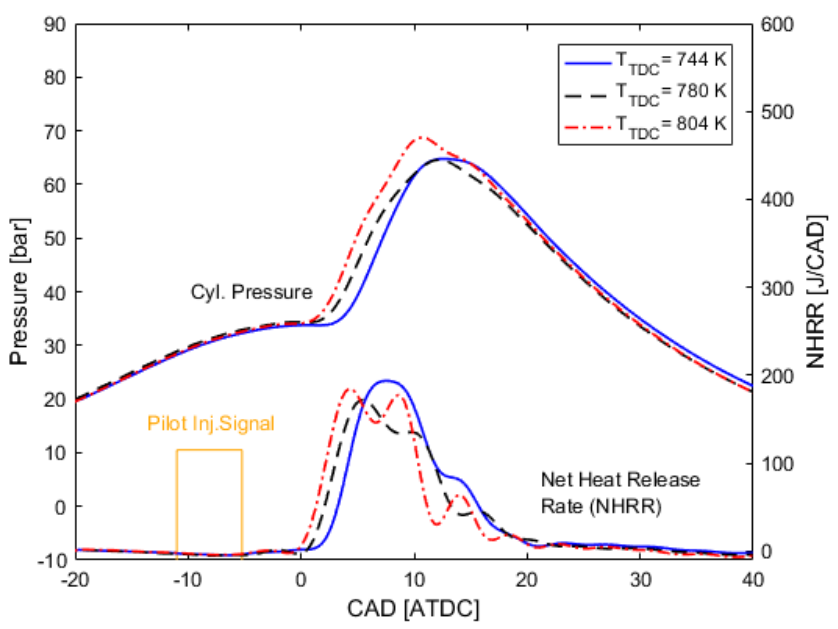

Figure 8. Mean cylinder pressure and net heat-release-rate curves at different $\mathrm{T}_{\mathrm{TDC}}$ and at $\phi_{\mathrm{CH} 4}=0.57$

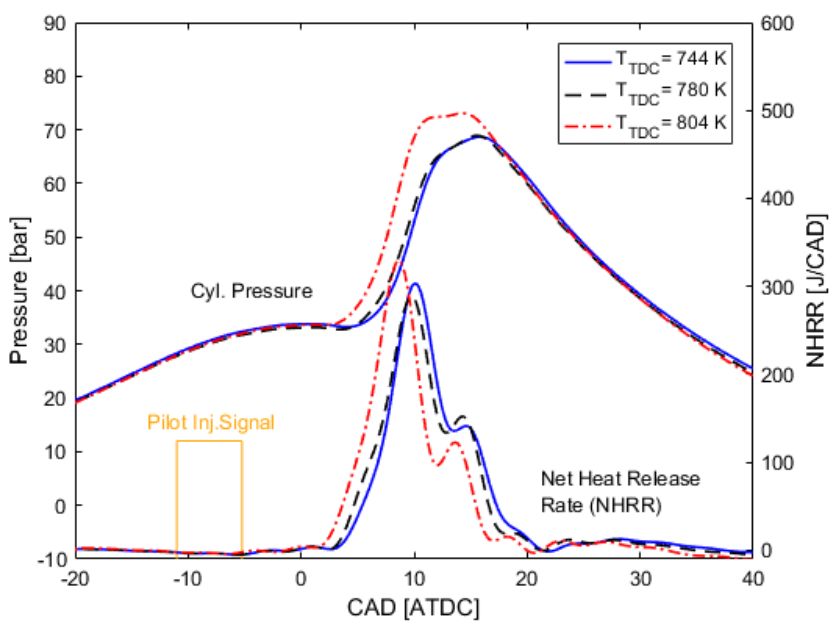

Figure 9. Mean cylinder pressure and net heat-release-rate curves at different $\mathrm{T}_{\mathrm{TDC}}$ and at $\phi_{\mathrm{CH} 4}=0.86$

Figure 4 compares the NL images of $\phi_{\mathrm{CH} 4}=0.57$ for different TDC temperatures, it is evident that when increasing the TDC temperature, 
the onset of ignition advances. At temperatures $780 \mathrm{~K}$ and $804 \mathrm{~K}$, the NL suggests that the combustion has already started compared to $744 \mathrm{~K}$. At temperature $804 \mathrm{~K}$, the start of combustion is earliest. The same trend is further supported by the corresponding HRR curves. The ignition delay trends observed in these DF test runs at three different TDC temperatures are presented in Figure 10. The addition of methane has an inhibiting effect on the ignition of diesel-pilot, and it extends the period of the pre-ignition processes of diesel-pilot as explained by Karim et al. [1][14] and Masouleh et al. [4]. Thus, higher temperature reduces the ignition delay while the rate of heat release slightly increases at the first stage of combustion.

Analyzing the HRR curves at a particular temperature with different methane equivalence ratios reveals that the ignition delay of DF combustion increases at richer conditions. This trend can be seen in Figure 10. The inhibiting effect of methane has a significant role in the ignition of diesel-pilot. Therefore, increasing the methane quantity and its concentration in the in-cylinder charge increases the ignition delay.

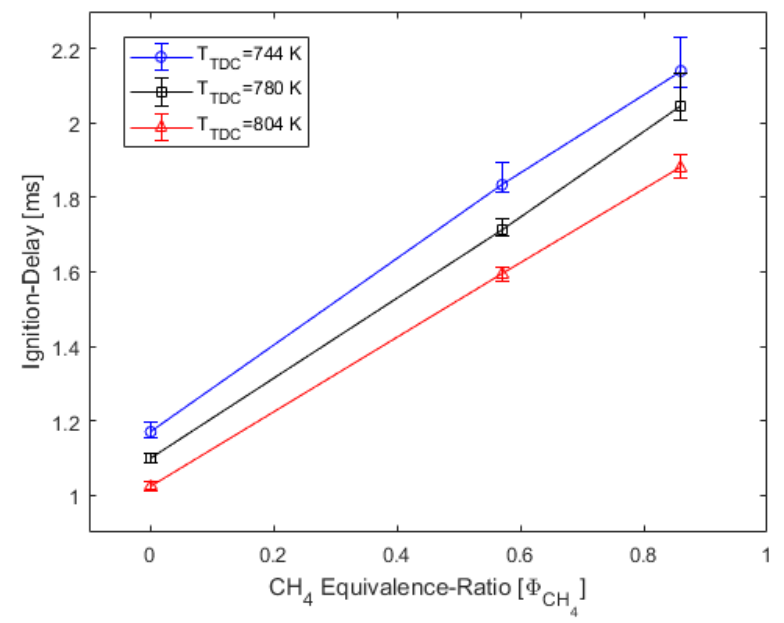

Figure 10. Ignition delay trends at different $\mathrm{T}_{\mathrm{TDC}}$

It should, however, be noted that there is ample motivation to explore DF combustion and ignition delay behavior on a wider range of equivalence ratios from leaner to richer conditions. Based on the HRR curves shown, it can be concluded that the shape of HRR in DF combustion is a function of TDC temperature, operating load conditions and the premixed gas-to-air equivalence ratio. Additionally, the HRR curves follow SI combustion behavior more closely [26], suggesting that the premixed turbulent flame front propagation is a dominant mode of combustion.

\section{Effect of Pilot Ratio (PR)}

The recorded NL images from PR-cases are presented as two columns in Figure 11. The images are arranged in each column with an interval of three CADs from the visible sign of the start of combustion. The outer boundary edges of two distinct flame-front reaction zones are shown in Figure 12. The images provide a comparison between the two pilot ratio cases as outlined in Table 4. In the present cases, PR tests have been conducted at a constant methane equivalence ratio. The methane-air mixture ignites near the cylinder wall and then the resulting premixed flame front propagates towards the center of the bowl.

Page 6 of 9
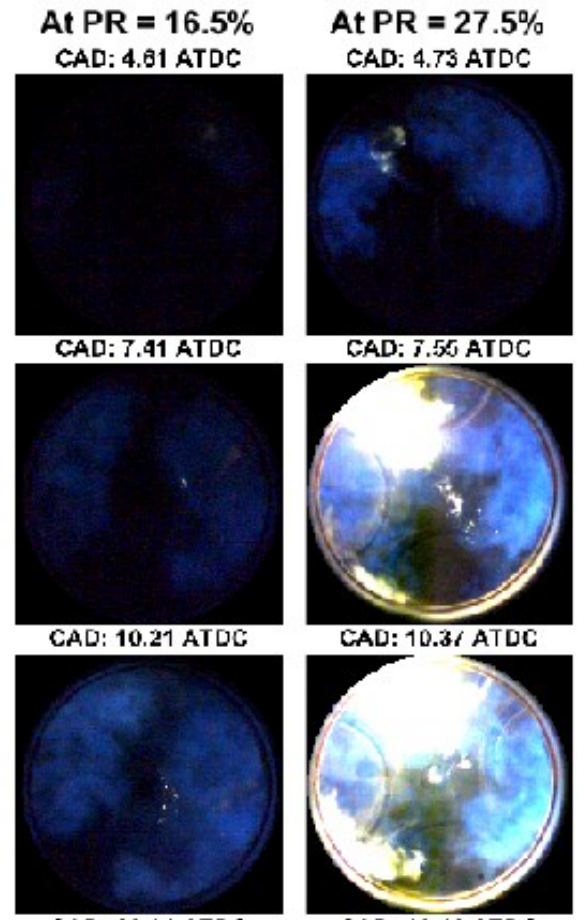

CAD: 13.01 ATDC
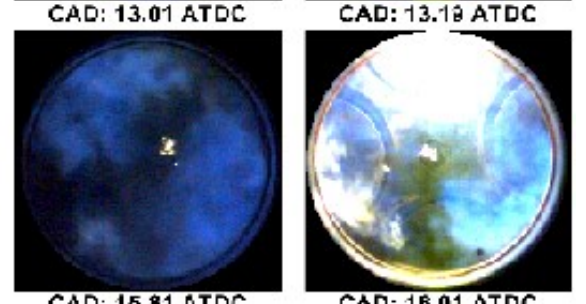

CAD: 15.81 ATDC
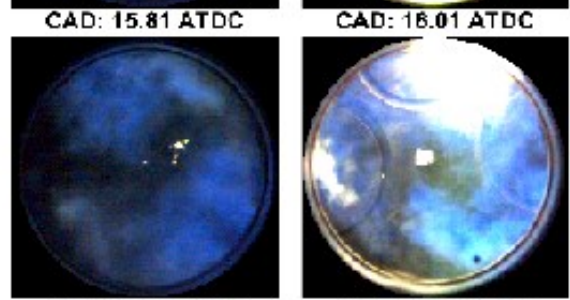

CAD: 18.61 ATDC
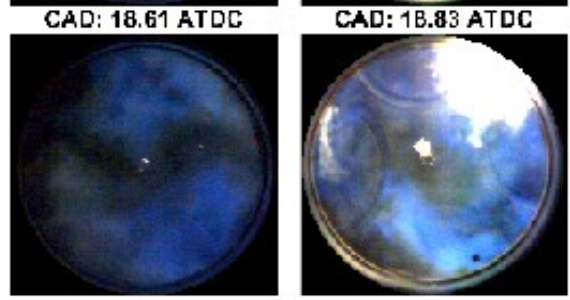

Figure 11. Representative NL images of DF combustion at $\phi_{\mathrm{CH} 4}=0.55$ and $\mathrm{T}_{\mathrm{TDC}}=744 \mathrm{~K}$
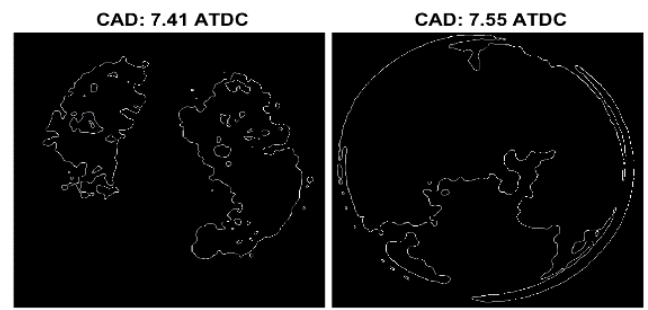

Figure 12. Boundary edges of two distinct reaction zones from the blue channel of NL images at $\sim 7 \mathrm{CAD}$ ATDC at $\phi_{\mathrm{CH} 4}=0.55$ (relative to Figure 11) 


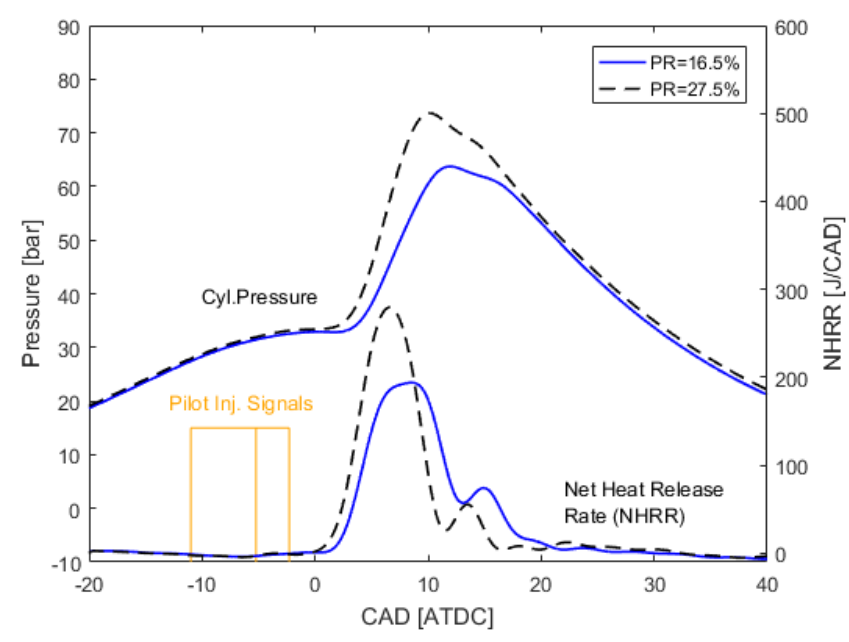

Figure 13. Mean cylinder pressure and net heat-release-rate curves for pilot ratio study at $\mathrm{T}_{\mathrm{TDC}}=744 \mathrm{~K}$ and $\phi_{\mathrm{CH} 4}=0.55$.

Comparing the images, it is evident that the combustion becomes more luminous with an increase in the diesel-pilot ratio. In the first column of Figure 11, there is a weaker flame propagation and the combustion at $\mathrm{PR}=16.5 \%$ is the less luminous compared to the $\mathrm{PR}=$ $27.5 \%$ case. However, with an increase in the pilot ratio, there is more diesel fuel available to entrain the larger volume of the methane-air mixture that causes an increase in the burnt fraction of the mixture and leads to a successful flame propagation, as also explained by Alla et al. [13] and Pettinen [21]. Therefore, at this lean condition $\left(\phi_{\mathrm{CH}}=0.55\right)$ with higher pilot ratio, a more luminous and an early start of combustion can be seen in the second column of Figure 11. Moreover, it was observed that at higher pilot ratio $(\mathrm{PR}=$ $27.5 \%$ ), localized high-intensity burning zones of vaporized dieselpilot can be seen near the periphery of the combustion chamber. The reason for this could be a sufficiently longer injection duration where the pilot injection stops at approx.-2 CAD ATDC and a faint evaporated pilot spray can be recognized at 4.73 CAD ATDC. For this longer injection duration, it seems that the diesel-pilot injected during the end part of injection inadequately mixes with the incylinder charge even with the strong in-cylinder swirl. Therefore, it is possible that some fractions of diesel-pilot forms locally rich mixtures which burn with high luminosity (soot incandescence at high temperature [20]). This has also been observed by Carlucci et al. [6] and Khosravi et al. [19].

The HRR curves for PR cases are presented in Figure 13, which depicts the DF combustion as a two-stage combustion, where the first significant peak refers to the first stage of combustion. The first stage is caused by the overlapping combustion phases of the premixed diesel-pilot and entrained methane-air mixture, while the second stage is caused by the combustion of the remaining unburnt methaneair mixture. Analysis of the HRR curves show that with an increase in the pilot ratio, the combustion becomes rapid and the rates of cylinder pressure and net heat-release increase, due to an increased load point operation. Moreover, the increased diesel-pilot amount increases the burnt fraction of the entrained methane-air mixture leading to a higher first stage HRR peak. However, the second stage HRR peak is then naturally decreasing.

The ignition delay trend observed during the studied PR cases is presented in Figure 14, which shows that the ignition delay decreases marginally with an increase in the PR. This trend can also be

Page 7 of 9 observed from the corresponding NL images and HRR curves in Figure 11 and 13, respectively. However, it is worth noting that the ignition delay of DF combustion is more sensitive to methane quantity and its concentration in the charge compared to the amount of diesel-pilot. The same observation has also been made by Gunea et al. [16] and Poonia et al. [17]. In addition, the ignition delay also gets effect by varying load point due increased pilot ratio, which increases combustion temperature. In summary, the employment of higher pilot ratio in the charge leads to a rapid and more luminous combustion that may be due to soot radiation. Furthermore, increased pilot ratio helps reduce the ignition delay mildly and sustain the successful flame propagation, especially at lean conditions.

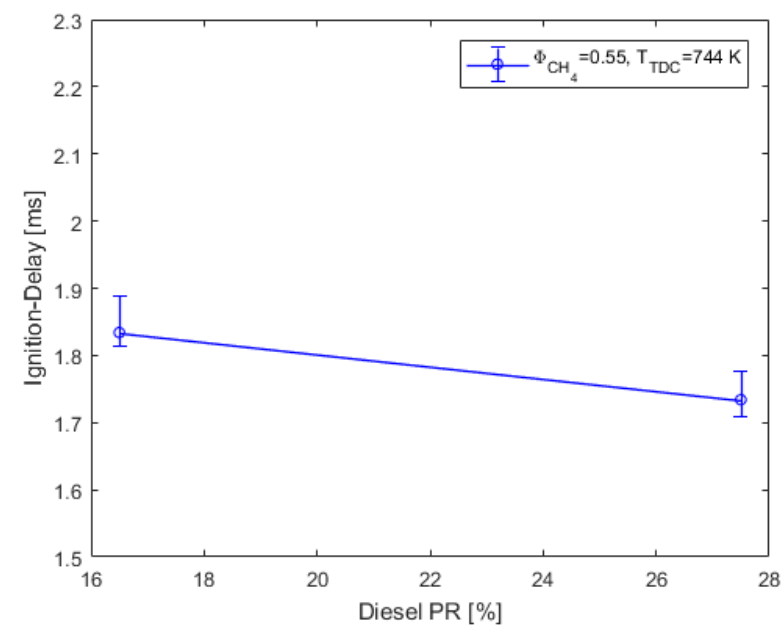

Figure 14. Ignition delay trend for different Pilot ratios at $\mathrm{T}_{\mathrm{TDC}}=744 \mathrm{~K}$ and $\phi_{\mathrm{CH} 4}=0.55$

\section{Conclusions}

The current study evaluates the sensitivity of the ignition process by investigating the effect of methane equivalence ratio, intake air temperature and pilot ratio on diesel-methane DF combustion. The experiments were conducted in a single cylinder heavy-duty diesel engine modified for DF operations with optical access. Methane was injected into the cylinder during the intake stroke through the intake manifold along with the air, and diesel-pilot was injected by a twohole injector close to TDC. The DF combustion was analyzed by means of NL images along with the corresponding cylinder pressure and net heat-release rate data. The observations made in these tests are as follow:

- The premixed methane-air mixture ignites near the wall of the combustion chamber with a high concentration of evaporated diesel fuel. The NL-images show two distinct reaction zones as a sign of the combustion start and flame development. These reaction zones grow and propagate towards the center of the combustion chamber. At high methane equivalence ratios closer to stoichiometric condition, prominent flame front propagation has been observed. However, at lean condition $\phi_{\mathrm{CH}}=0.57$, the flame propagation is weaker and the center of the combustion chamber was observed to be devoid of luminosity.

- DF combustion was observed as a two-stage combustion. Most of the heat release is from premixed combustion of methane-air mixture together with overlapping premixed diesel-pilot combustion, which suggests that premixed combustion is the dominant mode in DF combustion. The second-stage 
combustion is caused by the combustion of the remaining unburnt methane-air mixture.

- When increasing the methane equivalence ratio, the premixed combustion phase was observed to be stronger and the secondstage combustion was observed to be more prominent.

- At higher pilot ratio, the combustion becomes rapid and the heat release rate at the first stage increases marginally. The combustion becomes more luminous and at sufficiently higher pilot ratio, locally rich combustion zones burn with high luminosity. Moreover, the ignition delay decreases mildly with an increase in pilot ratio.

- The ignition delay was found to be a function of methane equivalence ratio, intake temperature and pilot ratio. It was observed that with an increase from $\phi_{\mathrm{CH} 4}=0$ to $\phi_{\mathrm{CH} 4}=0.86$, the ignition delay increases by a factor of $1.6-1.8$, depending on initial charge temperature. For example, at $\mathrm{T}_{\mathrm{TDC}}=744 \mathrm{~K}$ and $\phi_{\mathrm{CH} 4}=0$, the ignition delay is $1.17 \mathrm{~ms}$ while at $\mathrm{T}_{\mathrm{TDC}}=744 \mathrm{~K}$ and $\phi_{\mathrm{CH} 4}=0.86$, the ignition delay increases to $2.14 \mathrm{~ms}$. The ignition delay was found to be more sensitive to the methane equivalence ratio and TDC-temperature compared to pilot ratio.

In future studies, DF combustion will be studied both experimentally and numerically, with more detailed parameter sweeps and analysis of cycle-to-cycle variations. Additionally, optical diagnostics will be extended to draw more quantitative information about the ignition process.

\section{References}

1. G. A. Karim, Dual-fuel diesel engines. CRC Press, 2015.

2. S. Schlatter, B. Schneider, Y. M. Wright, and K. Boulouchos, "N-heptane micro pilot assisted methane combustion in a Rapid Compression Expansion Machine," Fuel, vol. 179, pp. 339-352, 2016.

3. G. A. Karim and K. S. Burn, "The combustion of gaseous fuels in a dual fuel engine of the compression ignition type with particular reference to cold intake temperature conditions," SAE Technical Paper 800263, 1980.

4. M. G. Masouleh, A. Wehrfritz, O. Kaario, H. Kahila et al., "Comparative study on chemical kinetic schemes for dual-fuel combustion of n-dodecane/methane blends," Fuel, vol. 191, pp. 62-76, 2017.

5. S. Schlatter, B. Schneider, Y. Wright, and K. Boulouchos, "Experimental study of ignition and combustion characteristics of a diesel pilot spray in a lean premixed methane/air charge using a rapid compression expansion machine," SAE Technical Paper 2012-01-0825, 2012.

6. A. P. Carlucci, D. Laforgia, R. Saracino, and G. Toto, "Study of Combustion Development in Methane-Diesel Dual Fuel Engines, Based on the Analysis of In-Cylinder Luminance," SAE Technical Paper 2010-01-1297, 2010.

7. R. Papagiannakis and D. Hountalas, "Combustion and exhaust emission characteristics of a dual fuel compression ignition engine operated with pilot diesel fuel and natural gas," Energy Convers. Manag., 2004.

8. K. Nithyanandan, Y. Gao, H. Wu, C.-F. Lee et al., "An Optical Investigation of Multiple Diesel Injections in CNG/Diesel DualFuel Combustion in a Light Duty Optical Diesel Engine," SAE Technical Paper 2017-01-0755, 2017.

9. S. Yoon and C. Lee, "Experimental investigation on the combustion and exhaust emission characteristics of biogasbiodiesel dual-fuel combustion in a CI engine," Fuel Process. Technol., 2011.
10. L. Wei and P. Geng, "A review on natural gas/diesel dual fuel combustion, emissions and performance," Fuel Processing Technology, vol. 142. 2016.

11. O. M. I. Nwafor, "Knock characteristics of dual-fuel combustion in diesel engines using natural gas as primary fuel," Sadhana, vol. 27, no. 3, pp. 375-382, 2002.

12. B. Challen and R. Baranescu, Diesel engine reference book. McFarland, 1999.

13. G. H. A. Alla, H. A. Soliman, O. A. Badr, and M. F. A. Rabbo, "Effect of pilot fuel quantity on the performance of a dual fuel engine," Energy Convers. Manag., vol. 41, no. 6, pp. 559-572, 2000.

14. G. A. Karim, "Combustion in gas fueled compression: ignition engines of the dual fuel type," Trans. Soc. Mech. Eng. J. Eng. GAS TURBINES POWER, vol. 125, no. 3, pp. 827-836, 2003.

15. G. A. Karim, W. Jones, and R. R. Raine, "An examination of the ignition delay period in dual fuel engines," SAE Technical Paper 892140, 1989.

16. C. Gunea, M. R. M. Razavi, and G. A. Karim, "The effects of pilot fuel quality on dual fuel engine ignition delay," SAE Technical Paper 982453, 1998.

17. M. P. Poonia, A. Ramesh, and R. R. Gaur, "Effect of intake air temperature and pilot fuel quantity on the combustion characteristics of a LPG diesel dual fuel engine," SAE Technical Paper 982455, 1998.

18. N. Dronniou, J. Kashdan, B. Lecointe, K. Sauveet et al., "Optical Investigation of Dual-fuel CNG/Diesel Combustion Strategies to Reduce CO 2 Emissions," SAE Int. J. Engines, vol. 7, no. 2014-01-1313, pp. 873-887, 2014.

19. M. Khosravi, J. Rochussen, J. Yeo, P. Kirchen et al., "Effect of Fuelling Control Parameters on Combustion Characteristics of Diesel-Ignited Natural Gas Dual-Fuel Combustion in an Optical Engine," in ASME 2016 Internal Combustion Engine Fall Technical Conference, 2016, p. V001T03A012-V001T03A012.

20. H. Zhao and N. Ladommatos, "Engine combustion instrumentation and diagnostics," Warrendale, PA Soc. Automot. Eng. 2001. 842, 2001.

21. R. Pettinen, O. Kaario, M. Larmi, "Dual-fuel combustion characterization on lean conditions and high loads," SAE Technical Paper 2017-04-0759, 2017.

22. J. Heywood, Internal combustion engine fundamentals. McGraw-Hill Education, 1988.

23. O. Kaario, E. Lendormy, T. Sarjovaara, M. Larmi et al., "InCylinder Flow Field of a Diesel Engine." SAE Technical Paper 2007-01-4046, 2007.

24. H. Belaid-Saleh, S. Jay, J. Kashdan, C. Ternel et al., "Numerical and experimental investigation of combustion regimes in a dual fuel engine," SAE Technical Paper 2013-24-0015, 2013.

25. U. Azimov, E. Tomita, and N. Kawahara, "Combustion and Exhaust Emission Characteristics of Diesel Micro-Pilot Ignited Dual-Fuel Engine," in Diesel Engine-Combustion, Emissions and Condition Monitoring, InTech, 2013.

26. M. Mittal, H. Schock, and G. Zhu, "In-cylinder Combustion Visualization of a Direct-injection Spark-ignition Engine with Different Operating Conditions and Fuels," SAE Technical Paper 2012-01-1644, 2012.

\section{Contact Information}

\section{Zeeshan Ahmad}

Puumiehenkuja 5A, 02150 Espoo, Finland Department of Mechanical Engineering, Aalto University zeeshan.ahmad@aalto.fi

Page 8 of 9 


\section{Acknowledgments}

This project has received funding from the European Union's Horizon 2020 research and innovation program under grant agreement no. 634135. The financial assistance is gratefully acknowledged. The author would like to thank Otto Blomstedt for his dedicated technical support in the engine laboratory.

\section{Definitions/Abbreviations}

DF

NL

IMEP

PR

HRR

CAD

SOI

ATDC

$\mathbf{T}_{\text {TDC }}$

$\phi_{\mathrm{CH} 4}$

ms

rpm

CW

CNG
Dual Fuel

Natural luminosity

Indicated mean effective

pressure [bar]

Pilot Ratio [\%]

Net heat release rate

[J/CAD]

Crank angle degree

Start of injection

After top-dead center

Temperature at top-dead

center

Equivalence ratio of methane-air mixture

millisecond

Revolutions per minute

Clock wise

Compressed natural gas 